\title{
Patterns of Congenital Heart Disease in Bangabandhu Sheikh Mujib Medical University, Dhaka:
}

\author{
NAVEEN SHEIKH, SAJAL KRISHNA BANERJEE, MOHAMMAD SAFIUDDIN, ATM IQBAL HASAN, DIPAL \\ KRISHNA ADHIKARY, SHIMA BHADRA, MD. MOSTAFIZUR RAHMAN BHUIYAN, CHAITY BARUA, GOPESH \\ RANJAN ROY, ELORA SHARMIN, MOHAMMAD MOBAROCK HOSSAIN \\ Department of Cardiology, Bangabandhu Sheikh Mujib Medical University (BSMMU), Dhaka \\ Address for Correspondence: Dr. Naveen Sheikh, Assistant Professor, Department of Cardiology, Bangabandhu Sheikh Mujib \\ Medical University, Dhaka, E-mail: sheikhnaveen@yahoo.com
}

\begin{abstract}
:
Congenital heart disease(CHD) is the most common congenital problem in children. Presentation can vary from asymptomatic, accidental finding to severe cardiac decompensation and death. Early recognition has great implication on prognosis. Our aim was to study age wise distribution and clinical spectrum of Congenital heart disease (CHD) in Bangabandhu Sheikh Mujib Medical University, (BSMMU), Shahbag, Dhaka. A retrospective analysis of 272 patients over a five year period was done. Clinical examination, echocardiography and Colour Doppler was used as diagnostic tools. Ventricular septal defect (VSD) was the common lesion (33.45\%) followed by Atrial septal defect (ASD) in $13.6 \%$ \& Patent ductus arteriosus(PDA) in $10.6 \%$. Tetralogy of Fallot (TOF)was the common cyanotic heart disease (15.8\%). Maximum number of children with heart disease 64\% was diagnosed between 0-5 yrs of age. This is a retrospective descriptive study on all patients with the suspected \& confirmed diagnosis of congenital heart disease referred for echocardiography over a period of 5 years from October, 2006 to December, 2011. Patients from day one of life till 18 years were included. Study was conducted in the pediatric cardiology dept. of BSMMU, Dhaka. Clinical examination, 2D echocardiography \& colour Doppler were considered as definitive tools for diagnosis of congenital heart disease.

We received patients from lower to upper middle class strata. We retrospectively analyzed the records of all paediatric first visit OPD (outpatient department) \& IPD (Inpatient department) patients between 0-18 years, during the same period. Children diagnosed with CHD were analyzed further. Preterms with PDA were followed up and not included in this study if it is closed spontaneously within the period of hospital stay or by managing conservatively
\end{abstract}

Introduction:

Paediatric Congenital heart diseases are relatively common with a prevalence ranging from 3.7 to 17.5 per 1000 live births ${ }^{1,2}$. It is a leading cause of death during the first year of life with a prevalence of $1 \%$ in live births $^{3}$. Early recognition of such lesions has great implications. Etiology of congenital heart disease(CHD) is multi factorial \& a large collection of environmental and genetic causes have a role in its pathogenesis ${ }^{4}$.

Congenital heart disease may present in different ages from birth to adolescent age group. Most cases are asymptomatic \& discovered during routine neonatal checkups. Other presentation can range from cyanosis, clubbing of fingers to full blown congestive heart failure. Malformation of cardiovascular system re also associated with significant medical morbidity, which requires use of costly medical facilities ${ }^{5}$. Thus determining the pattern of congenital heart disease is necessary to recommend the valuable changes in health policies ${ }^{6}$.
There is no information about the prevalence rate of congenital heart disease in Bangladesh, therefore the objective of this study has to estimate the pattern of congenital heart disease in the only referral medical university (BSMMU) in Dhaka, the capital city of Bangladesh.

Subjects \& Methods:

This is a retrospective study conducted in paediatric echocardiac room from Oct. 2006 to Oct. 2011 in BSMMU, Dhaka, all children with the confirmed diagnosis of Congenital heart diseases were included. 270 children were studied. Age ranged from day 1 to 18 years of age. Clinical data were revised. Consideration was given to total no of cases with congenital heart disease, age of diagnosis, sex distribution and type of congenital heart diseases. Different types of Congenital heart diseases considered for the present investigation are ventricular septal defect(VSD), atrial septal defect(ASD), tetralogy of fallot(TOF), patent ductus 
Table-I

Age wise distribution of congenital heart disease

\begin{tabular}{|c|c|c|c|c|c|c|}
\hline disease & $\begin{array}{l}\text { Total pt } \\
\text { according to } \\
\text { sex }\end{array}$ & $\begin{array}{c}0-5 \\
\mathrm{yr}\end{array}$ & $\begin{array}{l}5- \\
10 \\
y r \\
\end{array}$ & $\begin{array}{l}> \\
10 \\
\mathrm{yr}\end{array}$ & Total & $\begin{array}{c}\% \text { of total } \\
\text { Congenital } \\
\text { heart disease) }\end{array}$ \\
\hline AS(aortic stenosis) & $\begin{array}{l}\text { M: } 3 \\
\text { F: } 0\end{array}$ & 1 & 2 & 0 & 3 & 1.10 \\
\hline ASD(atrial septal defect) & $\begin{array}{l}\text { M: } 20 \\
\text { F: } 17\end{array}$ & 25 & 8 & 4 & 37 & 13.6 \\
\hline AV canal (atrioventricular canal defect) & $\begin{array}{l}\text { M: } 6 \\
\text { F: } 7\end{array}$ & 10 & 3 & 0 & 13 & 4.04 \\
\hline Co. Aorta(coarctation of aorta) & $\begin{array}{l}\text { M: } 3 \\
\text { F: } 0\end{array}$ & 3 & 0 & 0 & 3 & 1.1 \\
\hline DORV(double outlet right ventricle) & $\begin{array}{l}\text { M: } 5 \\
\text { F: } 3\end{array}$ & 7 & 1 & 0 & 8 & 2.94 \\
\hline PDA(patent ductus arteriosus) & $\begin{array}{l}\text { M: } 15 \\
\text { F: } 16\end{array}$ & 21 & 5 & 3 & 31 & 10.66 \\
\hline PS(pulmonary stenosis) & $\begin{array}{l}\text { M: } 7 \\
\text { F: } 4\end{array}$ & 6 & 5 & 0 & 11 & 4 \\
\hline Single ventricle & $\begin{array}{l}\text { M: } 3 \\
\text { F: } 2\end{array}$ & 3 & 2 & 0 & 5 & 1.83 \\
\hline TGA(transposition of great vessels) & $\begin{array}{l}\text { M: } 6 \\
\text { F: } 3\end{array}$ & 8 & 1 & 0 & 9 & 3.30 \\
\hline TOF(tetralogy of fallot) & $\begin{array}{l}\mathrm{M}: 32 \\
\mathrm{~F}: 11\end{array}$ & 24 & 10 & 9 & 43 & 15.8 \\
\hline VSD(ventricular septal defect) & $\begin{array}{l}\mathrm{M}: 51 \\
\mathrm{~F}: 40\end{array}$ & 68 & 20 & 3 & 91 & 33.45 \\
\hline
\end{tabular}

arteriosus (PDA), pulmonary stenosis(PS), transposition of great vessels (TGA), total anomalous pulmonary venous connection (TAPVC), P.atresia, single ventricle, Ebstein anomaly \& complex congenital heart disease.

Clinical examination, 2D colour doppler echocardiograph, ECG were considered as a definite tools for diagnosis of congenital heart disease. Variables recorded included the date of birth, sex, type of congenital heart disease. Patients with multiple congenital anomalies as syndromes were excluded. Premature babies were also excluded. Patients with acquired heart disease as Rheumatic defect or mitral valve prolapse, were not included as well.

Findings/Results: A total of 272 children were included. There were male 149 \& female 8 with a male female ratio of 1.52:1. 80.89\% total cases had acyanotic cardiac defects. Cyanotic heart defects were seen in 19.11\% pts. Ventricular septal defect (VSD) followed by atrial septal defect (ASD), patent ductus arteriosus (PDA), \& pulmonary valve stenosis were the commonest acyanotic congenital heart lesion 33.45\%, $13.6 \%$, $10.6 \%$ \& 40 \% respectively, whereas tetralogy of fallot $82.69 \%$ followed by transposition of great arteries 30\% were the commonest cyanotic heart lesion as shown in (table-2). Table 1 shows cardiovascular malformation distribution by sex. Female dominance of patent ductus arteriosus (PDA )\& atrio ventricular canal lesion(AV canal) were seen. Whereas a male dominance in the aortic valve lesion were seen.

Table-II

Cardiovascular malformation distribution by sex

\begin{tabular}{lcc}
\hline Congenital heart defect & Male & Female \\
\hline ASD & 20 & 17 \\
VSD & 51 & 40 \\
PDA & 15 & 14 \\
TOF & 32 & 11 \\
PAH (pulmonary artery hypertension) & 4 & 2 \\
PS & 7 & 4 \\
TGA & 6 & 3 \\
\hline
\end{tabular}


$\square$ Cyanotic $\square$ Acyanotic

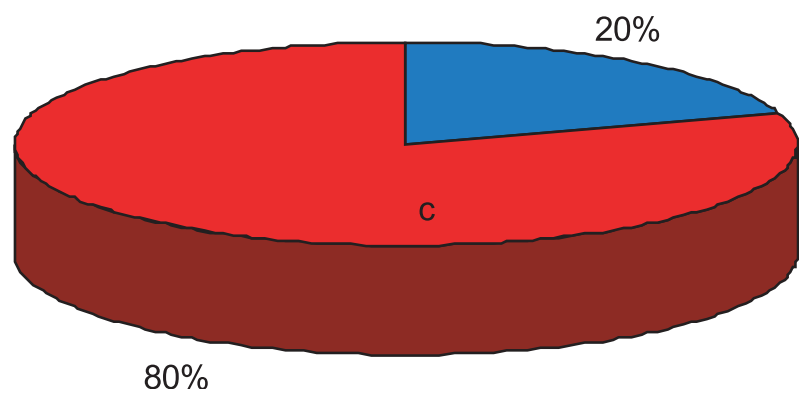

Fig.-I: shows type of $C H D$

\section{Discussion:}

Congenital heart diseases are an important group of disease that cause great morbidity and mortality in children ${ }^{7}$. This study don't give true incidence \& prevalence of congenital heart disease in total population since it is confined to BSMMU only \& this needs to be done on a large scale. The overall prevalence of congenital heart disease live births during this 2 year period was 6/1000 live births. This study was conducted to explore the pattern of congenital heart disease in BSMMU, Dhaka.

The most frequent type of congenital heart disease was found to be ventricular septal defect (VSD) (33.45\%), followed by atrial septal defect (ASD) (13.6\%), and patent ductus arteriosus (PDA )(10.6\%). The rate of VSD in males \& females were $1.27: 1$. The rate of ASD in males was 1.17:1. AV canal were found to be more common in males. PDA was found to be more common in male than female. Parents of (6.25\%) babies were related. None of the affected children had a positive family history of birth defects, hypertension, diabetes, thyroid disorder. History of still birth were found in $1 \%$ of mother - was Down syndrome. We found that congenital heart disease was more common in male birth.

There is no information about the prevalence rate of Congenital heart disease (CHD) in Bangladesh. Therefore the objective of our study had certain limitations. We do not have a facility for autopsy, so we cannot state the number of stillborn who had CHD as a cause of neonatal demise \& the number of severely ill children who died during initial steps of resuscitation (before echocardiography could be performed). Dropout rate of children born here and attending OPD is around 5\%, hence due to loss of follow up of many patients we could not assess the fate of very small acyanotic lesion like tiny Ventricular septal defect (VSD). We also do not know the outcome of the children referred for surgery to the cardiac centers. We found that CHD has more common in male births. The most frequent type of CHD was found to be VSD

It is generally accepted that the improvement of diagnosis, attention or awareness among general pediatrician \& early referral to pediatric cardiologists has resulted in an increase of reported prevalence of CHD. The present study indicates that CHD is an important pediatric cardiac problem in our study group. 149 cases were male (54.77\%) of CHD \& 98 were female (36.02\%). Male to female ratio is $1.52: 1.80 \%$ of cases were acyanotic CHD \& the remaining was cyanotic. It is inevitable that some cases would have escaped detection \& referral which mainly includes neotates born at home or who die without medical attention at home. VSD is found to be the most common acyanotic CHD (33\%) in our study. this is lower than that what is reported in other studies as shown in Table 3.

Worldwide ventricular septal defect(VSD) is the most common acyanotic CHD accounting $25-30 \%$ of all $\mathrm{CHD}^{8}$. This may be explained by the difference in genetic makeup \& ethnicity. Atrial septal defect (ASD) ranked second in frequency accounting for $13.6 \%$. Patent ductus arteriosus (PDA ) was seen in $10 \%$ of cases.

Table -2 shows age wise distribution of congenital Heart disease. VSD is the most common heart lesion (33.45\%). Acyanotic heart disease were present in $80.89 \%$ children. $19.11 \%$ had cyanotic heart disease. Maximum no of cases were seen in 0-5 years age group.

Among the cyanotic lesion tetralogy of fallot( TOF) was the commonest cyanotic CHD followed by transposition of great vessels (TGA). There was a female predomainance in PDA \& AV canal defect in 63\% \& 68\% respectively in our study. Male prevalence was seen in PS. The multifactorial etiology of CHD involves the chromosomal abnormality, maternal diabetes, smoking, teratogenic drug \& maternal infection during early pregnancy $^{9,10}$. CHD have multifactorial nature of inheritance $^{17}$. This emphasizes the importance of genetic counseling to patients with family history of CHD disease.

In our study echocardiography is considered gold standard for diagnosis of CHD. in conclusion this study gives only overview of the pattern of CHD at BSMMU. majority of patients with CHD detected have noncyanotic CHD. Tetralogy of fallot (TOF) is the commonest cyanotic lesion \& ventricular septal defect (VSD) non- 
cyanotic lesion. In order to avoid complication early detection of CHD is of utmost importance after proper management. 2D echo with Doppler examination forms the gold standard for diagnosis.

In conclusion, this study gives only an overview of pattern of CHD in BSMMU. Our study should be a base for a national pediatric database. We recommend the continuity of statistical studies in all hospitals in Bangladesh. Early referral of children with suspicion of CHD to nearest pediatric cardiac center for early treatment to improve the outcome.

\section{References:}

1. Ferencz C, Rubin JD, McCarter RJ, Brenner JI, Neil CA, Perry LW, et al. Congenital heart disease:prevalence at live birth. The BaltimoreWashington Infant Study. Am J Epidemiol 1985; 121: 31-36.

2. Bolisetty S, Daftary A, Ewald D, Knight B, Wheaton G. Congenital heart defects in Central Australia. Med J Aust 2004; 180: 614-17.
3. Jose VJ, Gomathi M. Declining prevalence of rheumatic heart disease in rural school children in India: 2001-2002. Indian Heart J 2003; 55:158-60.

4. Billett J, Majeed A, Gatzoulis M, et al. Trends in hospital admissions, in-hospital case fatality and population mortality from congenital heart disease in England, 1994 to 2004. Heart 2008;94(3):342-8.

5. Fixler DE, Pastor P, Chamberlin M, et al. Trends in congenital heart disease in Dallas County births. 1971-1984. Circulation 1990;81(1): $137-42$.

6. Vaidyanathan B, Kumar RK. The global burden of congenital heart disease. Congen Cardiol Today 2005;3:1-8.

7. Alabdulgader AAA. Congenital heart disease in 740 subjects: epidemiological aspects. Ann Trop Paediatr 2001;21(2):111-8.

8. Aburawi E. The Burden of Congenital Heart Disease in Libya. Libyan J Med, AOP: 060902. 2006.

9. Nelson Text Book of Pediatrics.17th edition 2004: 1499-1502.

10. Oxford textbook illustrated comparesion to medicine, 2001. PP 146-50. 